\title{
Flaws In Medicine Must Be Corrected: An Open Report to National Governments amid the COVID-19 Catastrophe
}

Jianqing $\mathrm{Wu}^{1}$, Ph.D., J.D.

April 20, 2020

(Work series paper, v1.00, NOT published in a journal)

Correspondence: tempaddr2@atozpatent.com

1. End the Incurable Era (Independent researcher for cause), P. O. Box 689, Beltsville, MD 20704. www.igoosa.com.

\section{ABSTRACT}

It is a common question why society is hopeless in the war against COVID19. Based on well documented evidence, the business model of traditional medical publishers is like a covert extortion against involuntary parties; researchers, academics, libraries, societies, editors, and peer reviewers. Each article is produced by the collective efforts of all involved parties. The publishers make profits by charging access fees and subscription fees. The unique position of the publishers arise from its power to decide article merit and societal needs to access articles. By examining their editorial policies, review practices, rejection reasons, etc., I found that their editorial policies are formulated to improve their financial positions but not medical merit. Strong support is found from analyzing several selected articles published by three key publishers. I found that their practices have the effects of perpetuating medical flaws and mistakes and promoting only profitable but inferior treatments. By engaging those practices for long times, they have created a pool of incomplete evidence that does not reflect human real ability to fight the disease. By relying on such incomplete evidence, governments cannot formulate sound public health intervention policies and society could not use cheap and more powerful methods to fight the disease. Most of the deaths and most of the severe economic damages to the U.S. could have been avoided. The mankind is paying ultimate prices in human lives and economy because government and society blindly rely on the incomplete evidence. By continuing relying on the incomplete evidence, humans continue various activities that have the effect of brewing future civilization catastrophes. I urge all governments to take legal actions necessary to protect disruptive medical discoveries, encourage competing arts, and expand medical evidence without regarding its form and source.

Keywords: traditional medical publishers, peer review, extortion model, medical discoveries, incomplete medical evidence, COVID-19, civilization catastrophe 


\section{INTRODUCTION}

In 2001, I discovered that medicine was established on a flawed foundation when I studied common law development history. Even though I had tried to bring this critical issue to the light of day, I did not get response, nor support. In this period, people died at 20 to 30 million a year from chronic diseases. After 2017 , I started doing self-funded research and resulted in several articles that prove four key presumptions in medicine (as well as many other practice theories) were incorrect. My finding provided a brief chance for society to address a civilization catastrophe like the COVID-19, traditional medical publishers suppressed my findings by refusing to review. They collectively killed this brief chance for society to better deal with this disease.

The COVID-19 is a mild disease, but has become disastrous pandemic that will not end soon. It can be brought under control by using extreme measures like locking-down cities. Medicine is not able to address overwhelming problems such as viral test errors, asymptomatic infections, relapsing infections, inconsistent incubation times, chronic diseases formation, viral transmission in animals, etc, any attempt to try to end this pandemic is unrealistic. A bulk of the world population will get this infection, and a huge number of people may die or get severe disability if an effective drug is not found in time.

From my own experience in dealing with medical publishers, I suspect that their practices are mainly responsible for the catastrophic medical landscape. I will examine their business model, their article selecting practice, and the pool of medical articles as primary evidence. Specifically, I try to find how they provide incentives for maintaining obsolete medical theories and practices, discourage disruptive medical discoveries, and suppress research articles challenging medical theories and practices, and how they deal with research articles promoting health arts that do not help them make profits. I then assess the validity of the medical evidence they have collected.

I will also try to understand how governments, academics, foundations, societies, etc. rely on the pool of medical evidence produced by medical publishers, why societies have relied on their articles as the sole evidence, and why World Health Organization (WHO) and governments use them as exclusive evidence. Finally, I will show why there are no predictable cures for chronic diseases, cancer and infection diseases like COVID-19, and what must be done to end the present COVID-19 catastrophe and prevent future civilization catastrophes.

\section{ANALYSIS}




\section{A. Medicine Was Established on a Flawed Foundation}

I will summarily prove that four core presumptions: population medicine, dualism, reductionism, and two-value disease classification are wrong or introduce far too bigger errors to make treatments invalid. However, those presumptions are not improper if they are used to understand health mechanisms, but are wrong whenever they are used as the basis of forming treatment protocols.

\section{Misuse of randomized controlled trials in medical studies}

Population study method is considered as the crown jewel of medicine. The method introduces three kinds of errors: indiscriminate application of treatments, inability to address interfering factors, and bundling interference factors into the error term to raise its variances [1]. Due to those problems, they introduce far too much and too many errors. Based on our mathematical model, multiple factor health optimizations are far superior to randomized controlled trial by tens to thousands times $(10-1,000$ s) [1]. This single problem is sufficient to reject most treatment methods developed by using controlled clinical trials.

2. Dualism has long been refuted in every major medical fields of study by thousands of published articles

Mind is an essential component for curing chronic diseases. If any aspect of the body changes, the mind changes in response to the body change. In response to changes in the body, neural signals from the brain for regulating the body are changed. To cure a disease, both parts must be changed at the same time. A treatment model without including mind is like altering shoe sizes without considering the feet. By focusing on only the body part, diseases are cured only by accident. Tens of thousands of studies concerning mind, emotion, chronic stress, etc. conclusively prove this model assumption is wrong. This same conclusion is found in specialized medical fields such as cancer, HIV, wound healing, heart disease, and influenza $[2,3,4,5]$.

\section{Reductionist treatment model}

The reductionist model also independently makes treatment methods fail. Reduction is possible for simple physical devices. Even for a moderate complex system, repairing by focusing one thing is not possible. There are more than 100 biochemical pathways and more than 25,000 genes. For any chronic disease such as heart disease, cancer, infection, and autoimmune disease, tens to thousands of factors affect disease outcomes [1, 2, 3]. Any attempt to fix a disease by using one single drug to alter one step of more than a hundred processes is an unrealistic over-simplified method. The only exception is to address foreign invaders where a single drug can be effective solution. Reductionist treatment model has failed in the entire history of medicine in treating chronic disease. When this method is used to evaluate surgery and chemotherapy, it grossly 
exaggerates their true performance in treating cancer [5]. COVID-19 disease can be modified by hundreds of factors that affect viral activities, immune responses, and waste removal efficiency [6, 7].

\section{Two-value disease classification}

The two-value disease classification is originated from common law courts but not a part of nature. The health condition of a person depends on a large number of factors, each of which makes a small amount of contributions to holistic health and diseases. Each of a large number of health properties can have $\pm 50 \%$ variations (reflected in the reference ranges of human laboratory data). However, we have shown that chronic diseases were developed over years to several decades and a disease is a result of less than one percent of departure from the values for maintaining required balance [1]; Severe lung damages may be caused by $0.1 \%$ over accumulation of white blood cells in the lungs [7]. When any disease is recognized only when altered imbalance hits certain mark, the method introduces additional errors and inaccuracies.

When a two-value scale (the binary scale) is used to model a health property, the scale naturally introduces excessive errors. It can introduce $50 \%$ or more, depending on the quantitative point for changing between the two values. A deviation of \pm (10\%-50\%) could be considered normal under the two-value scale (e.g., an organ function, even when $50 \%$ of organ function is lost, the person still has no sign of disease), but $\pm 0.1 \%$ departures from the ideal values may cause a chronic disease. The introduced errors are larger than diseasecausing departures by 50-500 times [1]. The two-value scale and all other problems are collectively responsible for the failure of preventive measures [3]. When the two-value scale is used to model drug side effects, most side effects escape from being identified because they could not pass the threshold of the side effects.

When public intervention measures are attempted on two values, such measures naturally fail [8]. An extinguished COVID-19 pandemic can be revived due to false negative viral test results, insufficient isolation times, virus transmitted by infected persons without symptoms, virus carried by animals or chronic viral carriers, etc. When up to $25 \%$ people may carry the virus without symptoms, and almost 30\% test results would be false, any attempt to extinguish the virus is a delusion. Only viable path in the long run is mitigating disease severity by treatment performance, improve population immunity, and raise personal resistance to the virus.

5. Research model exaggerates drug performance

While some drugs can have magic role in dealing infection and acute disease, their true benefits and side effects are not correctly determined due to method flaws. Randomized controlled trails are good at determining strong effect but cannot determine side effects realized on a long term. Moreover, research method used in evaluating drug side effects are also based on a special two 
values on the two-value scale: when the drug side effect is not observed, it is assigned as no (a zero value), when a side effect is found, it is assigned by different grades (e.g., one to four levels) [9-10]. Human organ has great capacity redundancy. The threshold of disability is much lower than the reserve capacity [3]. If a drug has just reduced $50 \%$ of an organ function, its side effect often cannot be found and attributed to the drug. Due to use of this method, side effects reducing major organ function will not be seen or felt until the drug has decreased their function to near the disability level. This is why most drug side effects are not known in clinical trials but are found in post-marketing surveillance. Unfortunately, post-marketing surveillance is ineffective [11]. In cancer cases, most serious side effects of cancer treatments were not known until a serious study found that the treatments shortened survivors' lives by as much as $30 \%$ from suffering accelerated aging-like damages [12, 13]. For those reasons, we found that surgery and chemotherapy actually shorten lives in most cases [5].

Table 1. Comparisons between the Medical Model and Health Optimization Engineering (HOE) using Ten Factors of Similar Effects

\begin{tabular}{|l|l|l|l|}
\hline Elements & $\begin{array}{l}\text { Medical Model } \\
\text { (RCT) }\end{array}$ & $\begin{array}{l}\text { Health Optimization } \\
\text { Engineering (HOE) }\end{array}$ & $\begin{array}{l}\text { Relative Error } \\
\text { rate/Inaccuracy }\end{array}$ \\
\hline $\begin{array}{l}\text { Research } \\
\text { Approach }\end{array}$ & $\begin{array}{l}\text { Focus on one } \\
\text { factor in a trial }\end{array}$ & $\begin{array}{l}\text { Focus on 10 factors } \\
\text { on individual person }\end{array}$ & $\begin{array}{l}\text { About 100 times difference: } \\
\text { Due to indiscriminate } \\
\text { application, negating effects. }\end{array}$ \\
\hline Dualism & $\begin{array}{l}\text { Ignore mind } \\
\text { and emotion; } \\
\text { Treat person } \\
\text { reactor }\end{array}$ & $\begin{array}{l}\text { Include mind and } \\
\text { emotional as part of } \\
\text { cure }\end{array}$ & $\begin{array}{l}\text { Medicine fails by certainty in } \\
\text { dealing with chronic } \\
\text { diseases. Central Nervous } \\
\text { System regulates the immune } \\
\text { system. }\end{array}$ \\
\hline $\begin{array}{l}\text { Reductioni } \\
\text { st }\end{array}$ & $\begin{array}{l}\text { All research } \\
\text { focus on one } \\
\text { step, thing or } \\
\text { aspect }\end{array}$ & $\begin{array}{l}\text { To address health as } \\
\text { whole, including } \\
\text { timing, phase, } \\
\text { mechanic properties, } \\
\text { etc. }\end{array}$ & $\begin{array}{l}\text { (Note reduction is proper for } \\
\text { understanding health } \\
\text { mechanisms but may not be } \\
\text { used to formulate treatments) }\end{array}$ \\
\hline $\begin{array}{l}\text { Two-value } \\
\text { disease } \\
\text { definition }\end{array}$ & $\begin{array}{l}\text { Every research } \\
\text { question was } \\
\text { turned into } \\
\text { two values: yes } \\
\text { or no }\end{array}$ & $\begin{array}{l}\text { Use all factors in a } \\
\text { quantitative scale } \\
\text { (rarely used) }\end{array}$ & $\begin{array}{l}\text { Medical model introduces } \\
\text { excessive inaccuracies by } \\
\text { using the two-value scale }\end{array}$ \\
\hline $\begin{array}{l}\text { Side } \\
\text { effects of } \\
\text { treatment } \\
\text { s }\end{array}$ & $\begin{array}{l}\text { Acknowledge } \\
\text { side effects } \\
\text { only when } \\
\text { "seeing" it: }\end{array}$ & $\begin{array}{l}\text { Diets, natural } \\
\text { products, physical } \\
\text { conditions, exercises, } \\
\text { etc. }\end{array}$ & $\begin{array}{l}\text { Failure to see lost organ } \\
\text { function reserve; and } \\
\text { exaggerate benefits of } \\
\text { surgery, drugs, radiation, etc. }\end{array}$ \\
\hline
\end{tabular}




\begin{tabular}{|l|l|l|l|}
\hline $\begin{array}{l}\text { Overall } \\
\text { performan } \\
\text { ce }\end{array}$ & $\begin{array}{l}\text { Failure in } \\
\text { curing } \\
\text { diseases }\end{array}$ & $\begin{array}{l}\text { Curing chronic } \\
\text { diseases require time } \\
\text { and efforts }\end{array}$ & $\begin{array}{l}\text { Due to excessive errors and } \\
\text { inaccuracies, medical model } \\
\text { is remote from reality of } \\
\text { human body. }\end{array}$ \\
\hline
\end{tabular}

The RCTs have utility when they are used in various circumstances. However, their findings in the two-value conclusions are often inaccurate. Even though the data without the layer of statistical analysis are useful, their conclusions cannot be applied to individual persons. Treatments based on a dualism model cannot cure diseases except by accident; treatments using limited factors developed by the reductionist model cannot cure chronic diseases except by accident. The two-value scale together with the flawed randomized controlled trials cannot detect each of a large number of weak causal factors but hide most side effects of synthetic drugs. They collectively turn medicine into an art that can control symptoms, stop pains and make patients comfortable. While some drugs can shorten infection duration, their side effects are underestimated.

\section{B. Medical Publishers "Determine" Article Merit By Weighting Amount of Profits}

Every scientific discovery must be judged by others. For example, when a person does a doctoral research, this research quality is judged by his advisory committee. In this case, the merit of research was normally determined without regarding the publication.

(1) Maintaining status quo is the key for maintaining stable flow of revenues

Traditional medical publishers do business and thus have incentives to select articles that can advance their commercial interests. When that is the core mission, merit of medical discoveries is not primary. However, to gain audience and sell the largest number of journals or articles, they must maintain content quality so that their articles will not disappoint their audience. Merit is secondary as compared with gain or loss in money.

Changes in research standard can have adverse impacts on publisher business. After medicine has become a mature profitable industry, everything including research model, medical theories, treatment methods, related social practices, medical insurance, related legal services, etc. has been integrated into the medical landscape. Changes to any aspect in the medical landscape would affect some vested interests and invited strong dissents. Obviously, changes in publication practices would have adverse impacts on their audience. In order to maintain their financial interests, they have strong inherent interest to maintain the status quo in medicine.

The right to select articles is controlled by editorial policies and screening process of medical publishers. In promoting their business, they naturally select articles that attract the largest audience. Their audience include medical doctors, practicing physicians, and private entities in business. Any articles that 
displease current audience, adversely affect current business practices, or hurt their professional reputation are expected to hurt their revenues.

\section{(2) Capitals for extortion is the power to select and publish articles}

Although the traditional publishing model was described as theft in a well known joke [14], it does not have a hidden conceal element. Medical publishers make money in subscription fees, one time access fee, and publication fees. All those fees are known to those who pay. Academics need to publish articles in order to have their research achievements recognized [14]. This is a vital step for maintaining their competitive positions. Academics may even benefit from the largesse of the publishers and such money may be used to support research programs. The publishers get moneys from academics and societies. The services of publishing companies are often provided by unpaid editors and unpaid reviewers. Their right to charge higher fees is due to their unique positions: the subject of research involves millions of dollars, running an experiment for many years, its real value is recognized upon publication. There is no point to add any risk on to the step of realizing their research value. Academics and researchers would not tolerate the slightest risks, and thus would not bargain for lower subscription fees.

A real problem arises from the academic demand for a large number of publications. When medical science has reached the current state of art, researchers have to know medical discoveries in many fields. They have to spend a great deal of money for subscription fees relative to their research and development budgets. This problem is common among all research institutes, universities, and researchers. This is how academics and researchers become volunteer subjects of extortion: they have to pay unreasonable fees. For similar reasons, the publishers can get free services from editors and reviewers because the publishers are in the position to judge the merit of their medical articles and discoveries. The society also becomes subject of extortion because they need to access vital medical knowledge. Access fee from $\$ 40$ to $\$ 70$ per article is unreasonable. The reviewers willingly work for the publishers in order to get free access to journal articles or to maintain a good relationship with the publishers.

By subsisting on this covert extortion model for decades, the publishers naturally learn how to maximize their profits. Obvious things are to maintain the largest basis of academics, please the largest number of libraries, recruit the largest number of unpaid editors, and enlist the largest number of volunteer reviewers. All of the four components can be achieved just by selecting articles. The publishers have financial interest to select articles that can attract existing audience, promote profitable medical options, but exclude research articles that do not attract existing audience and disrupt medical practices.

Due to the long research cycle, academics and researchers naturally need stability of publication standards. A change in foundation of medicine may disrupt existing research programs. Both the incentive in the unethical publishing model and long research cycles require the publishers to suppress 
disruptive medical theories, medical practices, and self-helping health art because they can diminish their common financial interests.

In the current environment, medical publishers naturally care about impact factors, which depend on the number of citations in a given time. A high impact factor implies an increased need to access the journal. To achieve and maintain the largest impact factor, the publishers have incentives to select articles that attract a largest audience by selecting hottest article subjects. What they naturally do is keeping competing health arts from entering the field, suppress medical discoveries, and even prevent medical discoveries within medicine from becoming cures.

(3) Bias and incompetence are common in peer review

The most famous piece of evidence on bias against authors comes from a study by DP Peters and SJ Ceci [15]. They took 12 studies that came from prestigious institutions that had already been published in psychology journals. They retyped the papers, made minor changes to the titles, abstracts, and introductions and changed the authors' names and institutions. They invented fanny institutions with names. The papers were then resubmitted to the publishers that had first published them. In only three cases did the journals realize that they had already published the paper, and eight of the remaining nine were rejected-not because of lack of originality but because of poor quality. The bias is not directed to persons, but was driven by the desire to publish papers for reputable authors and institutions. This bias can be traced to their desire to raise their impact facts or journal reputation. Even though those journals are not the leading medical publishers, the driving force for making this kind of erratic and biased editorial decisions is exactly same.

(4) Use peer review to stifle competition, dissents and challenges

It was found that "....peer review is a flawed process, full of easily identified defects with little evidence that it works" [16]. It was found that randomized trial of open review against traditional review [17] had no effect on the quality of reviewer opinions. Peer review may eliminate occasional mistakes, but this benefit could be achieved by editorial work [18]. The claim that peer review can improve research quality is an unrealistic expectation. This should be expected from the limited review time and poorly matched field expertise. For any article, authors are true experts in research subject while reviewers possess only general knowledge in the field. A scientific study is complex and inevitably people will take different views on its strengths, weaknesses, and importance [16]. Here the real problem is that the authors have done the research for many years, but peer reviewers can spend at most several hours.

Biggest abuses are stealing ideas from papers reviewed and present them as their own, or produce an unjustly harsh review to block or at least slow down the publication of the ideas of a competitor [16]. The mischief was found in the context without implicating a need to suppressing disruptive medical discoveries 
or competing health art. What is far important is suppressing disruptive medical discoveries and precluding challenges to wrong medical practices.

(5) Article "merit" is whether articles promote profits

By tracking money, I found that most of money comes from medical practices. Even donation and largesse are generated with intention to promote or find cures which are used in clinics.

To increase extortion capacity, the publishers naturally see the need to generate more cash by the medical industry. One obvious strategy is publishing articles to advocate the core idea that only drugs can cure diseases. The publishers naturally promote profitable medical options and reject articles that can adversely affect their profits. The notion of using drugs to cure diseases was formed by mistakes long before human immune system was understood. Yet, I could not find any proof that drugs can actually cure cancer, chronic disease, and COVID-19. Drugs can alter the dynamics between disease processes and healing processes. Even though some drugs can make big differences in some cases, real cures for challenging diseases are host responses and immune responses. Antiviral drugs can shorten flu disease course by about 1 day. However, this effect can be easily achieved by using a large number of different combinations of non-medical interventions. The publishers advocate this small benefit by a publishing a large number of medical articles, but including few or no articles on using non-medical options.

Medical publishers select articles mainly based on their effects on their profits. One obvious thing they naturally do is to develop treatments that can put patient names on a patient list but not cure them. That is the main reason that medical options can control symptoms for money but cannot cure diseases. This is why the U.S. is about to reach $\$ 5.7$ trillion medical spending by the middle century. Medical publishers use editorial policies and review practice to screen out medical discoveries, medical theories, and treatment methods that are expected to hurt their profits. By using accepted research standard, article structural requirement, word count, etc., medical publishers automatically preclude disruptive medical discoveries from becoming cures, discredit self-help measures, and prevent alternative treatment options. The bias built in their editorial policies can preemptively preclude even $99 \%$ medical discoveries in medicine form becoming treatments based on original studies in cancer $[1,2,4$, 5], aging and lifespan [3], and infection diseases [6, 7].

(6) Publishers prevent disruptive medical discoveries from seeing the light of day

The peer-review is used to preclude disruptive medical discoveries. First, as long as publishers and peer reviewers share their common interest, such review naturally becomes censorship for keeping out disruptive medical discoveries. Rejecting articles at the time of publication is the best time to kill competing arts. Second, true merit of medical discoveries cannot be judged at the time of publishing unless the subjects concern only incremental 
improvements. This can be seen from the long time windows required to test validity of medical theories and practices, and extreme difficulty to correct existing errors in medicine.

Many medical errors were corrected only after they had controlled medicine for long times. Cancer theories include homoral theory (Hippocrates's belief), lymph theory (Stahl and Hoffman), blastema theory (Johannes Muller, 1838), chronic irritation theory (Virchow), trauma theory (widely accepted belief from the late 1800s until the 1920s), infectious disease theory (Zacutus Lusitani, 1575-1642, and Nicholas Tulp, 1593-1674) [19]. The miasma theory (the miasmatic theory) once held that diseases, such as cholera, chlamydia, or the Black Death were caused by a miasma (e.g., "pollution"), a noxious form of "bad air", also known as night air. This theory was described in the 1st century BC and remained popular in the Middle Ages. It influenced the world for almost two thousand years. It was not until 1876 that the theory was definitively overthrown [20]. After a hundred years, the somatic mutation theory was found to be wrong for most cancers [21].

It is unwise to preclude medical discoveries or theories simply because peer reviewers lack subject expertise, lack ability to see non-obvious problems, lack personal experience in appreciating diseases, conduct a harsh review, or lack time to do thorough review. Moreover, early arrived medical discoveries are difficult to understand because corroborative medical discoveries and other supportive evidence are not available yet. If cancer will be cured by using predictable cures by using five pieces of discoveries; rejecting each piece of discoveries at each time of publication will prevent all of them from seeing the light of day. No cure will be found. Medicine keeps producing controversial findings due to use of reductionist model.

Rejecting articles in the publication stage can diminish societal ability to correct fatal errors in medicine. This is why surgery is misused in treating cancer for more than a century. An early consensus qas that use of surgery should be restrained except under special circumstances. One incorrect medical finding around 1908 fuels incentives to use surgery to remove cancer. I found the following evidence: (1) surgery was found in a well designed animal study to promote cancer spreading in 2018, (2) exercises, lifestyles, foods and nutrition were found to provide great survival benefits in thousands of studies (mainly after 1980), (3), no good study has been done to prove surgical benefits on survival times, (4) organ reserve capacity concept has gained gradual acceptance, (5) a large number of patient stories on surgical outcomes are available online, implying that the surgery raised cancer growth speeds, (6) observed surgical side effects were noted in many research articles, (7) cancer self-resolution were known in several hundred documented cases and estimated millions of undocumented cases, (8) finally, we found that randomized controlled trials were incapable of generating valid evidence for weak treatment effects. When all pieces of the evidence are analyzed under the same kinetic framework, 
we had to conclude that surgery is an unwise treatment option in most cases. This mistake cannot be determined without combining them.

The mankind has a compelling interest to see disruptive medical discoveries to appear and see wrong medical practice corrected. Those interests cannot be protected without stopping the censorship practice of medical publishers.

I found that the combination of the reductionist model and the publishers' censorship have played main roles in precluding cures for most diseases. This combination now brings the catastrophe that threatens human life.

(7) Publishers practices evolve from covert extortion to outright fraud

To gain widespread acceptance, medical publishers set editorial polices which appear to be even-handed on face. They use predetermined and published editorial policies for selecting articles. Their policies are written for promoting their revenues. Scientific merit of medical articles may be considered ONLY after the articles have passed editorial screening. They consider a large number of trivial factors including word limitation, citation format, writing style, topic, institution affiliation, etc. New English Journal of Medicine limits total word count to 2700 words for article. Some journals also require precisely article sectional structure. Such endless limitations favor reductionist-based articles and exclude holistic articles. When such editorial policies are combined with biased internal and external reviews, they select only articles of the type they favor. When my articles are submitted, they could reject purely for inability to comply. Due to distinctive nature of my articles, my articles cannot comply with their requirements.

Their editorial policies are what their editors interpret and use. Their screening processes consider how an article affects their fee-paying audience, reactions of their experts and their existing revenue channels. Their screening always has the effect of precluding the holistic model, lifestyle-based measures, and all kinds of combination measures. Thus, their publications have the effect of promoting synthetic drugs and a few money-driving things as treatment options. Essentially, their editorial practices have built-in rejections for any article that does not fall within any of their favored options before the world has a chance to see.

If an article exposes a foundational flaw in medicine, they do not review it but suppresses it. The publishers use in-house reviewers. When they rejected an article, they are not required to make any comment. In fact, in all my experience, they could not tell one good reason. This implies that they do not even need to understand articles. They did not need to think about the subject, implications, and consequences. In the last half a year, New England Journal of Medicine, Science, Nature, Lancet, and even CDC journal all have done exactly the same: ask me to place the article in better places. When science is molded on this extremely narrow template, what the publishers promote is a junk science. 
It is hard to understand how the publishers decided whether not they would review my article. Both titles and abstracts of my articles show clear intention to challenge the core presumptions in medicine. If my finding were proved to be right, it could correct major flaws that harmed human life for a long time. This was not a small issue that any reviewer could avoid and pretend that nothing had happened. It is especially so because the open science moment would save my articles. One possibility is that they had used the practices for so long that they could not see what have changed. They just kept doing it for one more time. It is also possible that those reviewers just made a determination of article types even without understanding substances and consequences.

The lack of controversy in their suppression practices does not diminish their culpable mind. Their past actions to promote flawed medicine cannot be challenged because no body was able to prove. The most harsh arguments one could make are that challenged medical interventions may shorten human lives and new interventions may extend human lives [5]. My challenges are very different. It takes out the whole medicine. If the publishers have made knowingly decisions without justification, their conducts would be far worse than extorting money. A difficult problem is that the publishers and reviewers were on notice of the serious flaws which could affect a huge number of human lives and the health of civilization, thus their conduct is equivalent to committing fraud.

Under tort laws of many states, the publishers conduct may be actionable by those who died from using clearly wrong medical treatments. They suppressed truth for monetary gain and those who died acted by relying on published articles. Only one requirement that publishers could defend is whether they made representation. However, most state laws do not require express statement, conduct like nodding head, failure to act, failure to correct known mistakes could be enough. In addition, it is possible that their conduct has violated criminal statutes in some states. In addition, their conduct may also be negligent. Publishing the massive junk articles may be excused because medicine is an incremental science and mistakes and inaccuracies are prevalent in their articles. However, their deliberate act to collect and promote only one kind of articles with intent to conceal medical flaws is entirely a different thing.

When COVID-19 has turned the world upside down, medical publishers continue preventing medical discoveries from seeing the light of day. In treating COVID-19 diseases, the most important articles concern treatment strategies [6, 7]. All of their articles concern discoveries of drugs which can generate money. By their rapacious publication practices, they are responsible for this catastrophe, the loss of a large number of human lives, the crippled national and the world economy.

\section{Article Compositions Show Medical Publishers Promote Flaws and Preclude Disruptive Medical Discoveries}


I will discuss some articles from several leading medical publishers. My purpose is to show how medical publishers endorse only research articles within an extremely narrow scope of treatment options.

\section{New England Journal of Medicine promotes junk science}

In the TAILORx trial, adjuvant endocrine therapy and chemoendocrine therapy were found to have similar efficacy in certain women (with hormonereceptor-positive, HER2-negative, axillary node-negative breast cancer who had a midrange 21-gene recurrence score) [22]. This trial enrolled 10,273 women at 1,182 sites in the United States, Australia, Canada, Ireland, New Zealand, and Peru. At 9 years, the two treatment groups had similar rates of invasive diseasefree survival (83.3\% in the endocrine-therapy group and $84.3 \%$ in the chemoendocrine-therapy group).

The design was based on the assumption that a same treatment is good for a population (e.g., the difference between individual persons can be ignored). One could expect that hazard events depend on individual patients. The patients are greatly different in age, menopausal status, tumor size, histologic grade, etc. In addition, there must be great differences in interfering factors such as exercise, diet, emotional states, lifestyle factor, etc. The impacts of those factors can be very large [1]; and even emotion and exercise can have big impacts than those differences between the two treatments [4]. The presumption that all subjects within a treatment are similar does not hold.

A big flaw is that percent numbers with statistical analysis are used to tell performance differences between two treatments. The numbers are useful to show how the two treatments perform for the population. However, the finding cannot be used on individual patients. Such few parameters have no magic power to predict who fall into statistics of adverse events and who do not. The statistical analysis was used to evaluate hazard radios, but both randomized factors and all uncontrolled interference factors affect adverse events and the hazard ratios.

The trial does not answer three questions that every patient could beg to know. First, the trial does not tell which treatment is better for a particular patient among the 6711 patients. It is possible that endocrine therapy is better for $\mathrm{N}$ number of patients, and chemoendocrine therapy is better for $\mathrm{M}$ patients. Both $\mathrm{N}$ and $\mathrm{M}$ could take the same values but filled with different patients to achieve the same outcome. I imagine that if the two treatments were tailored to different patients, they could achieve better outcome (e.g., 95\%). Second, 15.7\% to $16.7 \%$ of the 6711 participants experienced at least one of three adverse events within nine years. The total number is estimated to be 1090. The trial does not tell who experience it and who does not. Finally, patients experienced adverse events in different orders. Who died earlier and who died later are also important to patients, but the article does not answer those questions.

Besides the flaws we have proved in our study [1], population trial is not a right method for developing best treatment protocols. It is expensive and 
inconvenient to use such trials to finally adjust treatment parameters such as dosages. Obviously, most trials are not used to optimize treatment protocols. If a population trial is used to compare two treatments as in the TAILORx trial, what can be determined are the responsive rates of patients for the two treatments. By increasing patient number and trial site number, what could be changed are differing response rates (e.g., which of the two treatments are better). This is not a matter that a specific patient concerns. Which of the two treatments is better for a specific patient depends on the patient condition. The treatment effect on a patient does not depend on how other patients respond. If one treatment is better for patients in the U.S. and the other is better for patients in New Zealand, why selection of treatments in the U.S. should be influenced by what is better in New Zealand? This method can only produce a universal protocol which is actually not good for any patients because the conclusion is based on improper averaging of the contributory effects of races, human genomes, cultures, lifestyles, disease conditions, etc. Trials for studying chronic diseases are different from trials designed to test a strong effect: the destructive power of a new weapon found in New Zealand may be used as a good indication in the U.S. Running massive TAILORx trials is like an attempt to improve weighing accuracy by using thousands of household scales to weigh chemical reagents in many locations. The trial cannot improve accuracy, but makes the result worse. Chemotherapy problems should be addressed by different methods.

Medical publishers favor this kind of trials because all parties can profit with little benefits for patients. New England Journal of Medicine has an interest in promoting profitable activities of the medical enterprise, and naturally suppresses articles to challenge such practices.

\section{Nature endorses flawed research model and inferior treatment options}

Nature makes this statement: "Randomized controlled trials are clinical trials in which at least two interventions - the test treatment and a control treatment - are simultaneously evaluated in two or more arms of the trial, with enrolment into each arm determined by a random process that ensures freedom from bias. They have been the gold-standard of clinical trials for decades [19]" This statement could be correct before it was challenged.

I searched from Nature articles containing randomized controlled trials and found several scientific reports [24-29]. The articles adhered to the goldstandard of clinical trials in all aspects from experimental designs, data collection, statistical analysis, to conclusion. They reflect the same limitations I have pointed out in Section A. All of those articles make the same assumption that population trials are good. None of them consider whether a measured property is interfered by interfering factors and the sizes and number of the factors. Such studies cannot rule out a much better treatment approach: a large number of weak factor combinations in longer time windows. They do not focus on the role of mind. Their findings cannot rule out much better interventions that use multiple health factors plus emotional interventions. Finally, all of them follow the two-value convention which naturally introduces excessive errors. 
The conclusion of daily L-dopa use [27] is only limited to its exact experimental condition. It may be true for the experimental population, but may be not true to a specific person in the trial or outside the trial; the outcome is true for the population (e.g., an abstract person) under the dosage and experimental condition; this finding may be true in the specific use amount, but it may have different results if L-dopa is used in a lower dosage for a longer time or is used in combination with other foods or natural products. The data is useful because it indicates one particular outcome.

In the current medical research culture, authors have to reach a conclusion rather than just leaving the data without rendering a conclusion. It is possible the data may be used to support different conclusions when tens of new pieces of evidence are found. However, no author can have their articles published without rendering a conclusion. This is a common law court practice. Even a narrower conclusion is not reliable because how L-dopa affects other health properties is not investigated. It is possible that L-dopa may have other beneficial or adverse effects that were neglected.

A potential negative effect of this research-based conclusion is that such conclusion can have long lasting adverse effects in medicine. If each of five studies reached an incorrect conclusion, but their data, when they are analyzed together, would have supported a different conclusion, the individual conclusions in the five studies would have a long-term affect in molding the thinking in the relevant subject. Due to this long-term effect, it would be impossible for those within the field of medicine to accept the new conclusion.

If Nature is charged with responsibility to determine merit of articles and the direction of medical research, it should be aware of my articles on randomized trials [1] and surgical and chemotherapy's roles from many pre-print servers [2]. My challenge is that even though a household scale can measure grocery, it cannot be used to weigh chemical reagents in an analytical laboratory. All research articles do not pay attention to this sensitivity requirement.

Due to its business model, Nature naturally could not accept any articles that teach health arts that are contrary to current medical practices. Nor does Nature invite anyone to submit articles on health optimization method, which could beat population-based treatments by hundreds times and conclusively end the incurable era. Nature is believed to bring great medical discoveries, but the narrow types of research articles reveal its true role of promoting the failed medicine.

\section{Lancet favors the misuse of randomized controlled trials}

In an article on a research method, Lancet editorial article correctly state: "They (Nobel Prize laureates) decided to break down the problems into smaller manageable questions and use empirical data to examine which interventions work and which do not, and what motivates people to make the choices they make. They used RCTs to assess the causal effects of an intervention" [30]. It states: "Of course, other study designs and approaches, such as more qualitative 
analyses, aid our understanding of health and development too, but the RCT remains the best means of discovering whether any proposed intervention may work." Lancet missed the most important issue: why the approach that Nobel Prize laureates used were better. The article did not touch the most important question: what are other interfering factors that might affect trial outcome and what are the effect sizes of the interventions relative to the interfering factors?

All influencing factors to poverty are visible, and personal habits contributed to poverty can be identified on personal basis, and interventions can be identified. Lancet states: "The lesson from this year's Nobel Prizes is that one size does not fit all.... In conceiving and doing rigorous experiments to find out what really works, we need to listen to the voices of the poor and design interventions that respond to their beliefs, needs, and expectations." Lancet stresses democratic approach, but overlooks human physiology. While economy can be an important factor, if intervention violates natural law governing human physiology, the measure must fail.

Lancet cited Hope 4 study as support [31]. In this trial, the investigators tested whether a model of care involving non-physician health workers, primary care physicians, family, and the provision of effective medications, could substantially reduce cardiovascular disease risk. The intervention included treatment using tablet computer-based simplified management algorithms and counseling programs; free antihypertensive (community available combination pill) and statin medications (10 mg rosuvastatin or $20 \mathrm{mg}$ atorvastatin) recommended by NPHWs but supervised by physicians; and support from a family member or friend to improve adherence to medications and healthy behaviors. Despite the great conclusion the study reached, I must question its conclusion. I know from my extensive study that a large number of factors affect blood pressures; and if interventions are rated by population trials, they must be stronger enough to get the blessing of statistical analysis. This is why the medical options are always drugs.

Lancet in its editorial article correctly questioned: why would someone be expected to take a tablet for high blood pressure for life when they feel perfectly well? By using the flawed medical model, any attempt to use one single factor would fail to show benefits [1]. Each weak intervention factor can be defeated by effects of hundreds of other interfering factors. Thus, each of them would be rejected in turn. By using the flawed research method, each study always ends with no cure, no benefit, except a drug, which has strong effect to get the blessing of statistical analysis. This is an inevitable result from using the flawed research model. However, such a finding can never prove that medication is best or the only intervention.

The casual statement that the intervention has no safety concern is patently inaccurate. Both atorvastatin and simvastatin have been associated with more than 50 case reports of liver injury and other statins have been implicated in this type of liver injury as well. Idiosyncratic liver injury due to statins has been reported to occur $1.9 \%-5.5 \%$ of patients in prospective series of drug- 
induced liver injury [32]. A study found that adverse reactions to antihypertensive medicines were reported by a total of 93 of 514 (18.1\%) patients. Common drugs can cause difficulty sleeping, flushing of the skin, muscle aches, frequent micturition, dizziness, nausea or vomiting, abdominal cramping or pain, dry irritating cough, bloating or gas, diarrhea, constipation, headache, etc. Adverse reactions resulted in the discontinuation and substitution of therapy in $49.5 \%$ of the patients [33]. Moreover, the long-terms impacts of using the drugs should be presumed to be bad on the elderly [34, 35, 36] and people with a history of breast or prostate cancer [37]. Furthermore, statintreated individuals undergoing immunotherapy for cancer may be at increased risk for worsening cancer [37-38]. Statins may cause autoimmune diseases [3943] even though the findings are disputed.

Concerning the controversy, American Heart Association made an opinion that Statins both protect the heart and lower cancer death risk [44]. If high blood pressure is not brought under control, it can damage the heart as well as kidneys, lungs, liver, etc. It is not surprising to see reduced vascular risk and reduced cancer risk compared with placebo [45]. This double reduction benefit does not alter my challenge even the slightly. First, the true degree of side effects are underestimated because they can diminish organ reserved function without any sign (what is recovered is unknown). Second, a large number of factors affect blood pressure and high blood pressure can be corrected by using any of many combination methods. Since medical model is designed to affirm only strong drugs, it naturally precludes non-medical treatments. In the period approximately 10 years after completion of the trial, the risk of death from coronary heart disease or nonfatal myocardial infarction was $10.3 \%$ in the placebo group and $8.6 \%$ in the pravastatin group; over the entire follow-up period, the rate was $15.5 \%$ in the placebo group and $11.8 \%$ in the pravastatin group [46] this small benefit was achieved at unknown costs. I have no slightest doubt that any of a large number of combinations using lifestyles, exercise, emotional management, and environment factors can reduce vascular risk, stroke risk, cancer risk, autoimmune disease risk, kidney failure risks.... Finally, the study has not disclosed potential long-term harm if the patients use them in their life times.

The true finding should be qualified by two conditions. If a patient cannot restore vascular health by healthy lifestyle and exercise, the medication intervention may have benefits; and however, the long term risks from drugs side effect are unknown. Those articles show that Lancet favors the drug options that can generate revenues for the medical industry.

(4) AAAS does the same practices

In one time, I thought that American Association for the Advancement of Science (AAAS) is different from traditional medical publishers, so I tried to have some of my articles published. In one submission, I challenged the legal presumptions in medicine. I was informed that my article was not rated with enough scores and there was no enough interest. I was shocked by the 
statement. If my challenge is successful, it dismantles the foundation of medicine. In another attempt, I got a response that they do not publish "this type of article". I construe her reason of rejection as that my article does not follow the reductionist model. After the rejection, I found that the substance in my articles is directly contrary to what she had written over years: everything in compliance with population approach, dualism, reductionism, and two-value system. She would not publish an article discrediting her lifetime achievements. Even though AAAS gets donations in the name of promoting sciences, what it actually promotes depends on what its editors want. AAAS's mission fails for two reasons. By its short vision, AAAS fails to provide a platform that allows authors to by-pass the constraints of the failed medicine. Another reason is that it still uses peer review. My article challenge the research model, but AAAS uses peer review, but I cannot name my own reviewers.

\section{Medical Publishers Create an Invalid Pool of Medical Evidence to Promote Failed Medicine for Their Maximum Common Profits}

\section{Publishers created an invalid medical knowledge pool by manipulation}

By using orchestrated editorial policies and review process, the medical publishers have created a pool of medical articles for the world to use. The bulk park of the articles is revolved around biochemical and physiological pathways. That is actually the greatest part of medicine. However, what is terribly wrong is in the treatment part. I can see millions of articles on drugs and things that can be used to make profits, but too few articles on using non-medical options such as lifestyle, exercise, massage, mechanical actions, food, nutrition, natural products, air, water, vapor, temperature, pressure, emotion, habits, thinking/mind training, physical properties, detoxification, pollutants control, etc. to cure diseases. No articles disclose home remedies (they exist in millions); no case reports are published to explore how a terminal cancer patient suddenly self-resolve. I can find a large number of articles on temperature's roles, but no article discusses how to use temperature to prevent, cure and mitigate influenza. From my own experience, I found it is not because no body submits such articles, but because the publishers preempt the field by routinely rejecting and suppressing such articles.

Based on my studies in cancer, heart disease, and COVID-19, no good argument can be made that the non-medical inventions are inferior to drugs, surgery, and radiation. Exercise is the most powerful and safest cures for almost all chronic diseases, and it was used in most, if not all, ancient medicines for thousands of years. I have personally used exercise for decades. Even though a large number of studies found that exercise has great curative benefits, but they did not discuss details on using exercises. By using the randomized controlled trials to evaluate everything at the fast action pace, each study could reach a wrong conclusion. Thus, we heard that nothing can cure chronic diseases. By using reductionist approach, studies naturally preclude everything that does not support their revenues. However, I have proved that if those factors are 
combined, their long-term curative power can be one to four orders of magnitudes more powerful than correspondent medical interventions.

The publishers' merit review system precludes articles exposing the medical flaws. As long as treatment methods are developed under the flawed medical model, the treatments can only control symptoms but cannot cure diseases. When the flaws were unknown, they could not know the reason for failure of medicine. However, after medical publishers are on notice of the flaws, their actions to preclude challenges is not innocent. By suppressing challenges, they could continue promoting harmful treatments in the name of "sciences".

Federal agencies, academics, researchers, etc. have common interest to defend the medical system. They all have professional responsibilities to defend medical practicing standards. They may defend the flaws for various reasons. Some of them never think the possibility that the medicine is built on a flawed foundation; some may be driven by the present financial gains without thinking devastating consequences; and others may lack visions. My challenge is not just about monetary gain or loss; it is about medicine future, its existence, massive human lives and even civilization continuation. Uncorrected flaws in medicine are deemed to affect each person in the world. Everyone may die from chronic diseases in almost 0.7 total chances and gets cancer in his and her life time by 0.4 chances. If I further adjust inaccuracies introduced by the two-value system, the medical flaws most probably affect everyone through environment pollutants, massive food additives, and undisclosed drug side effects.

2. They have successfully established a medical culture that accept only their manipulated incomplete medical evidence and discredit competing health art.

By decades of propagation, medical publishers have convinced the world that the medicine is "science" mainly by relying on medical evidence from randomized controlled trials. Medical publishers promote themselves by selecting the types and subjects of articles like repeating the voice of defending medicine.

The publishers influence medicine by influencing experts, who run government agencies, manage health care industry, and write public opinions. The experts propagate medical articles to further the interest of the medical industry. By publishing a large number of articles, they successfully convey their voice to fortify the validity of the flawed medicine.

As a result of their influences and joint promotion, most people cannot evaluate medicine independently. I sent a series of articles to selected officials in FDA, the NIH, CDC, and federal agencies, selected U.S. senators, selected House Representatives, the White House, university professors, experts in medicine, etc. concerning flaws in medicine. I periodically invited them to review my findings. None of them reviewed and responded. Everyone may assume that article merit should be determined by medical publishers. The NIH has tens of thousands of scientists, but many of them told me that federal polices do not 
allow them to review articles from outsiders. If this rule is directed to an article on how to save flies, the policies may make sense. The policies do not distinguish between flies and potentially billions of human lives. The world has formed a perfect interlocked system to preclude disruptive medial discoveries or challenges, and have no ears to hear questioning flaws in medicine. Nobody knows that medical publishers engage in article selection practice resulted in complete medical evidence.

While nobody cares about medical flaws and medical truth, every person including governmental official, media member, and private person looks to published articles for guidance. Everyone assumes that sound, valid, and lifesaving medical discoveries are brought to the world by medical publishers. The world has blindly trusted in the merit of medical articles. Most scientists will not consider a scientific discovery as valid unless it has been approved by peer review [47]. Researchers generally cannot cite unpublished articles because relying on unpublished articles may prevent them from getting grants. Libraries do not accept unpublished articles because they cannot be subscribed, and national library of medicine accepts only peer-reviewed articles that have been accepted [48].

Federal agencies do not use unpublished articles in making policy decisions except unpublished legislative materials. The NIH employed a dual peer review system which is mandated by statute in accordance with section 492 of the Public Health Service Act and federal regulations governing "Scientific Peer Review of Research Grant Applications and Research and Development Contract Projects" [49]. Even universities, research organizations, and federal laboratories cannot use research articles that have not been peer reviewed and published [50]. With massive research funds and a huge number of research scientists, they cannot determine article merits independently, but rely on the rapacious merit assessment which is just as good as a publication-for-money trade.

Media generally do not cite and comment unpublished articles. Influenced by propagation by media, most people have been misled to believe that only articles published by leading medical publishers teach good medicine, and nothing can cure diseases. Most foundations and non-profit organizations do not fund research on concepts that have not peer-reviewed and published; doctors cannot consider treatment protocols that have not been reviewed and published. The blind trust by the world provides great opportunity for rapacious extortion practice. This interlocked medical landscape guarantees that medicine can only produce ineffective and dangerous treatments that have proved to fail time and again.

Even World Health Organization (WHO) and Center for Disease Control and Prevention (CDC) rely on the invalid pool of medical evidence. The WHO kept saying that it lacks evidence that supports the use of masks by uninfected persons; and the CDC has done exactly same. By seeking evidence only from the incomplete evidence pool, they can only see small improvements by surgery and 
drugs, but cannot see evidence showing the flaws of medicine and harmful effects of surgery and chemotherapy [1,51]. Due to exclusion of evidence, they cannot see most case reports, personal observations, home remedies, fork treatments, patient stories, personal experiences, etc. They naturally cannot see medical findings involving disease process timings, factor interactions, multiple weak variables, and curative roles of lifestyle factors [6, 7]. In the end, they have to ignore the indisputable truth that chronic can be cured and echo the same lame excuse: there is no cure for cancer, chronic diseases, and COVID-19. They ignored hundreds of cases reflecting cancer self-resolution and the huge differences in COVID-19 disease severity.

Relying on incomplete evidence is the reason for the poor performance the public intervention measures in most nations. One obvious reason against use of masks is that China's practices was ignored by WHO and CDC. Such evidence was not in the pool of peer-reviewed articles and cannot be used in the medical culture. After China locked down cities, people were required to wear masks in grocery stores and food markets. Due to high human density, people are often in unavoidable physical contacts in those public places. Only masks have prevented them from getting new infection. This piece of evidence is conclusive, and should have trumped all known research articles on COVID-19 or related viruses. The costs of relying on the publishers' incomplete evidence is the rapid spreed of the disease in the world. In the U.S. five cases will quickly become a million, but China could contain the largest initial outbreak even though its human density is much higher than U.S. The large number of deaths and worldwide economic damages could have been avoided but for the incomplete evidence.

One question I ask is how can the whole world relies on this rapacious article selection practice in medicine? I assume it was not a problem in the very early time and the problems have been aggravated by sequential amendments of national laws in Western nations. Each of legislative amendments increases the degree of dependence of societies on medical articles without ever considering their credibility. The influences are gradually expanded in societies and finally have reached non-common law nations. Before the flaws in medicine were exposed, nobody knew what is wrong except that most people know that medicine could not find cures for chronic diseases and cancer. This problem is gradually exacerbated by blindly relying on flawed medicine and incomplete medical evidence.

When the world has placed its trust in this rapacious merit system, it is inevitable to see this worst catastrophe and the mankind must pay the ultimate prices in human lives.

\section{E. Catastrophic Health Landscape in the World}

Due to many flaws, medical technologies are unable to accurately evaluate specific health problems for specific persons. Since the research model is remote from reality, medical validity is promoted in the name of science, but not the merit of curing diseases. 
1. Virtually all chronic diseases are listed in incurable diseases [52]. The total number of annual premature deaths is estimated to be about 30 million in the world. However, it was found by irrefutable evidence, lack of exercise is the major cause of chronic disease. This finding in combination with our filings [1], one should find that exercise alone can be cure for most chronic disease in most cases if exercise is properly used.

2. There are no predictable cures for cancer, but I found hundreds to thousands of things can be used to alter disease outcomes. Even exercises could reduce death rate by as much as 50\% [4, 53-56]. Exercise is much more powerful than surgery and chemotherapy if their benefits are viewed in a long term [5].

3. To make more profits, medical publishers naturally promote those medical options for commercial gain and suppress treatment options such as lifestyle, exercises, emotional management, environment factors, etc. They keep publishing articles with message that "only drug can cure diseases," which was formed long before knowledge of human immune system was unknown. Yet, I could not find convincing proof that drugs can cure cancer, chronic disease, and COVID-19. Even though in limited cases, drug interventions can make real difference to life and death, the real cures for all challenging diseases are host responses and immune responses. The obsolete notion has caused people overly rely on medical options that simply rarely work.

4. In treating COVID-19, medicine focuses on one single intervention factor. This approach must be poor in general because people are different [57, 58]. Medicine ignores irrefutable evidence that disease severity depends on hundreds of known factors (potentially thousands of unknown factors). It is clear that multiple factors can be used to alter diseases severity from no symptoms to death. Due to the reductionist approach, medicine precludes multiple factors as treatments. Concerning COVID-19 disease, we found that hundreds of things can be used to mitigate lung damages. However, medical publishers keep publishing articles echoing the same no-cure excuse. As long as the world continues to rely on medicine, the U.S. and world will lose a large number of lives. Now, this pandemic has disrupted personal life, business, social order, and all economic activities in the U.S. and most other nations.

5. The failure to find cures is responsible for the predicted failure of national health care system. The annual economic impact on the U.S. economy of the most common chronic diseases is calculated to be more than $\$ 1$ trillion, which could balloon to nearly $\$ 5.7$ trillion by the middle of the century [58]. Even worse, the COVID-19 pandemic suddenly makes the U.S. economy far worse. Morgan Stanley releases new forecast showing U.S. economy may drop as much as $38 \%$ for the second quarter [60]. If the U.S. continues relying on the incomplete medical evidence and extremely narrow treatment options, the nation will pay much higher price in both economy and human lives.

6. I have personally observed many people who died very quickly after they were diagnosed with cancer or terminal diseases. A common scene is that they 
went through extensive chemotherapy with a goal to kill "Every cancer cell", which is completely unrealistic and impossible.

7. A much serious problem is that the flawed research methodology is brewing much severer risk to civilization and human survivals. Population trials are unable to detect each weak effect among tens to thousands of other weak factors [1]; and two-value conclusions in studies conveniently dismiss each of all weak quantitative effects as "harmless" because it falls short to reach the flipping point on the two-value scale. This systematic error always works like a justification for abusive use of unnecessary and avoidable compounds, drugs, pollutants, etc. Abundant evidence shows that both animal and human immune systems can be severely suppressed by toxic substances $[1,4,5]$. Pollutants should be viewed as the main reason for increasingly prevalent infectious diseases such as COVID-19. If the mankind continues relying on controlled trial findings, it is a matter of time to experience catastrophic pandemics that may wipe out a large number of humans. This problem must be addressed by using a wise presumption that non-essential compounds should be avoided.

If an issue affects the health of civilization and human existence, the issue must be decided by considering evidence far beyond the scope set by rapacious medical publishers. Governments should consider articles that are not peerreviewed, not published, contrary to accepted teaching, and challenging the established art. They should include credible observations, stories, online reports, personal stories, common sense, etc. as in the court that decides a case.

\section{CLOSING REMARKS}

The business model of medical publishers is similar to covert extortion practice, by which the publishers get money from academics and societies, and also steel human lives and health of civilization. This business model is primarily responsible for maintaining this flawed foundation of medicine. To improve their extortion position, they do whatever necessary to suppress disruptive medical discoveries, conflicting medical theories, self-helping health arts, and superior medical treatments. The peer review system has been used to stifle competing health art which is magnitudes more powerful and safer than drugs. By suppressing medical discoveries for the long history, they have created a small pool of medical discoveries that promote only money-making medical treatments. By relying on flawed randomized controlled trials as final arbiters, they have successfully kept more than $99 \%$ of medical discoveries from becoming treatments, prevented the world from seeing cures for chronic diseases and cancer, and promoted poor or dangerous medical treatments. This business model is responsible for failure of medicine, lack of cures, mass premature deaths, and the present COVID-19 catastrophe. By relying on the incomplete evidence pool, governments and societies cannot see flaws in medicine, better 
medical treatments, and the need for overhauling medicine. Thus, the mankind will never see a day of ending the incurable era.

The mankind is paying ultimate prices in terms of human lives and economy, and nature is brewing more civilization risks. Due to media influences, most people do not even know what has caused incurable diseases and premature deaths. To correct the flaws in medicine, I urge governments to take immediate actions to outlaw this publishers' extortion practice, prohibit peer review practice intended for improper purposes, require publishers to separate publication decisions from article merit evaluation, impose a firm duty on medical publishers to correct flaws, mistakes and fraud in similar or more effort by which the publishers have promoted them. To prevent his kind of catastrophes from happening again, I urge governments to financially support open access movement and open science framework, and establish a future legal framework that will ensure that medical articles cannot be suppressed by any person and any challenge to obsolete, wrong, wasteful and rapacious medical theories and practices will be heard in established legal channels.

\section{SUPPLEMENTARY INFORMATION}

This report will be amended periodically. New versions may include graphic illustrations. Anyone is authorized to use it for research, personal knowledge, and legal advocacy for reforming medicine and culture of using medical evidence.

\section{CONFLICT OF INTEREST}

None.

\section{REFERENCES:}

1. Wu, Jianqing and Zha, Ping, Randomized Clinical Trial Is Biased and Invalid In Studying Chronic Diseases, Compared with Multiple Factors Optimization Trial (November 4, 2019). Available at SSRN: https://ssrn.com/abstract=3480523 or http://dx.doi.org/10.2139/ssrn.3480523. https://www.researchgate.net/publication/336699251

2. Wu, Jianqing and Zha, Ping, A Cancer Theory: The Central Nervous System's Adaptive Changes Make Chronic Diseases Incurable (November 4, 2019). Available at SSRN: https://ssrn.com/abstract $=3480562$ or 
http://dx.doi.org/10.2139/ssrn.3480562;

https://www.researchgate.net/publication/336775211

3. A_Multi-Factor Model for Estimating Relative Lifespans and Extending Health Spans. Accessed at https://www.researchgate.net/publication/337900952

4. Wu, Jianqing and Zha, Ping, Safe and Predictable Cancer Cures (November 26, 2019). Available at SSRN: https://ssrn.com/abstract $=3493825$ https://www.researchgate.net/publication/337547448_Safe_and_Predicable_Canc er_Cures

5. Wu, Jianqing and Zha, Ping, Surgery, Chemotherapy and Radiotherapy Promote Cancer Growth Speeds and Shorten Patient Lives (November 14, 2019). Available at SSRN: https://ssrn.com/abstract=3487080 DOI:

10.13140/RG.2.2.17967.28321

6. Wu, Jianqing and Zha, Ping, Treatment Strategies for Reducing Damages to Lungs In Patients with Coronavirus and Other Infections (February 6, 2020). Available at SSRN: https://ssrn.com/abstract=3533279; https://www.researchgate.net/publication/339077708_Treatment_Strategies_for Reducing_Damages_to_Lungs_In_Patients_with_Coronavirus_and_Other_Infection $\mathrm{s}$

7. Wu, Jianqing and Zha, Ping, Preventive, Mitigating and Treatment Strategies for Containing or Ending The COVID-19 Pandemic (a first update) (February 25, 2020). Available at SSRN: https://ssrn.com/abstract=3544428 or http://dx.doi.org/10.2139/ssrn.3544428

8. Wu, Jianqing and Zha, Ping, Public Health Intervention Framework for Reviving Economy Amid the COVID-19 Pandemic: A Concept (April 8, 2020). Available at SSRN: https://ssrn.com/abstract $=3571775$ or http://dx.doi.org/10.2139/ssrn.3571775

9. Pearce A, Haas M, Viney R, Pearson S-A, Haywood P, Brown C, et al. (2017) Incidence and severity of self-reported chemotherapy side effects in routine care: A prospective cohort study. PLoS ONE 12(10): e0184360. https://doi.org/10.1371/journal.pone.0184360.

10. Cornelius VR, Perrio MJ, Shakir SA, Smith LA. Systematic reviews of adverse effects of drug interventions: a survey of their conduct and reporting quality. Pharmacoepidemiol Drug Saf. 2009 Dec;18(12):1223-31. doi: 10.1002/pds.1844.

11. Golder S, Loke Y and McIntosh HM. Room for improvement? A survey of the methods used in systematic reviews of adverse effects. BMC Medical Research Methodology 2006,6:3.

12. Cupit-Link MC, Kirkland JL, Ness KK, et al. Biology of premature ageing in survivors of cancer. ESMO Open. 2017 December 18. 
13. López-Otín C, Blasco MA, Partridge L, et al. The hallmarks of aging. Cell 2013;153:1194-217.

14. Smith R. The highly profitable but unethical business of publishing medical research. J R Soc Med 2006;99:452-456.

15. Peters D, Ceci S. Peer-review practices of psychological journals: the fate of submitted articles, submitted again. Behav Brain Sci 1982;5:187-255.

16. Smith R. Peer review: a flawed process at the heart of science and journals. J R Soc Med 2006;99:178-182.

17. van Rooyen S, Godlee F, Evans S, Black N, Smith R. Effect of open peer review on quality of reviews and on reviewers' recommendations: a randomised trial. BMJ 1999;318:23-7.

18. Lock S. A Difficult Balance: Editorial Peer Review In Medicine. London: Nuffield Provincials Hospital Trust, 1985.

19. American Cancer Society. Early Theories about Cancer Causes. Accesse d at https://www.cancer.org/cancer/cancer-basics/history-of-cancer/cancercauses-theories-throughout-history.html. Last Accessed on November 8, 2019.

20. Koch R. "Robert Koch (1843-1910)". www.sciencemuseum.org.uk. Archived from the original on 25 January 2016. Retrieved 15 January 2019.

21. Brücher B, Jamall IS. Somatic Mutation Theory - Why it's Wrong for Mo st Cancers. Cell Physiol Biochem 2016;38:1663-1680.

22. Sparano JA, Gray RJ, Makower DF et al. Adjuvant Chemotherapy Guided by a 21-Gene Expression Assay in Breast Cancer, Engl J Med 2018; 379:111-121.

23. Nature. Title in response to search term Randomized Controlled Trials accessed at https://www.nature.com/subjects/randomized-controlled-trials.

24. Chong GO, Lee YH, An S-H. Efficacy of a chitosan tampon in the loop electrosurgical excision procedure: A prospective randomized controlled study. 07 April 2020, Scientific Reports 10, 6017

25. Hung S-Y, Chen H-C \& Chen W T-L. A Randomized Trial Comparing the Bowel Cleansing Efficacy of Sodium Picosulfate/Magnesium Citrate and Polyethylene Glycol/Bisacodyl (The Bowklean Study). 27 March 2020, Scientific Reports 10, 5604

26. Basolo A, Hohenadel M, An QY et al. Effects of underfeeding and oral vancomycin on gut microbiome and nutrient absorption in humans. 23 March 2020 Nature Medicine 26, 589-598.

27. Lebedev AV, Nilsson J, Nilsson J et al. Effects of daily L-dopa administration on learning and brain structure in older adults undergoing 
cognitive training: a randomised clinical trial. 23 March 2020. Scientific Reports 10,5227

28. Villafaina S, Collado-Mateo D, Domínguez-Muñoz, F.J. et al. Effects of exergames on heart rate variability of women with fibromyalgia: A randomized controlled trial. Sci Rep 10, 5168 (2020).

29. Kalem, Z., Namli Kalem, M., Bakirarar, B. et al. Intrauterine G-CSF Administration in Recurrent Implantation Failure (RIF): An Rct. Sci Rep 10, 5139 (2020).

30. Lancet Editorial. Where next for randomised controlled trials in global health? www.thelancet.com Vol 394 October 26, 2019

31. Schwalm J-D, McCready T, Lopez-Jaramillo P. et al. A Community-Based Comprehensive Intervention to Reduce Cardiovascular Risk in Hypertension (HOPE 4): A Cluster-Randomised Controlled Trial. 2019 Oct 5;394(10205):12311242.

32. Björnsson ES. Hepatotoxicity of Statins and Other Lipid-Lowering Agents. Lancet 2017 Feb;37(2):173-178.

33. Olowofela AO, Isah AO. A Profile of Adverse Effects of Antihypertensive Medicines in a Tertiary Care Clinic in Nigeria. Ann Afr Med. 2017 Jul-Sep; 16(3): 114-119.

34. Shepherd J, Blauw GJ, Murphy MB, et al. on behalf of the prosper (Prospective Study of Pravastatin in the Elderly at Risk) study group. Pravastatin in elderly individuals at risk of vascular disease (prosper): a randomised controlled trial. Lancet. 2002;360:1623-30.

35. Hunt D, Young P, Simes J, et al. Benefits of pravastatin on cardiovascular events and mortality in older patients with coronary heart disease are equal to or exceed those seen in younger patients: results from the lipid trial. Ann Intern Med. 2001;134:931-40.

36. Wenger NK, Lewis SJ, Herrington DM, Bittner V, Welty FK on behalf of the Treating to New Targets Study Steering Committee and Investigators. Outcomes of using high- or low-dose atorvastatin in patients 65 years of age or older with stable coronary heart disease. Ann Intern Med. 2007;147:1-9.

37. Hoffmann P, Roumeguère T, Schulman C, van Velthoven R. Use of statins and outcome of bcg treatment for bladder cancer. N Engl J Med. 2006;355:2705-7.

38. Goldstein MR. Do statins prevent or promote cancer? Curr Oncol. 2008 Apr; 15(2): 76-77.

39. Wolf VL \& Ryan MJ. Autoimmune Disease-Associated Hypertension. Current Hypertension Reports (2019) 21:10. 
40. Chang C, Gershwin ME. Drug-induced lupus erythematosus: incidence, management and prevention. Drug Saf. 2011;34:357-374.

41. Vasoo Sheila. Drug-induced lupus: an update. Lupus. 2006; 15:757-761.

42. Araújo-Fernández S, Ahijón-Lana M, Isenberg DA. Drug-induced lupus: Including anti-tumor necrosis factor and interferon induced. Lupus. 2014; 23:545-553.

43. Borchers AT, Keen CL, Gershwin ME. Drug-induced lupus. Ann N Y Acad Sci 2007 Jun; 1108; 166-82.

44. American Heart Association, Statins may do double duty on heart disease and cancer. January 6, 2020. American Heart Association News. Accessed at https://www.heart.org/en/news/2020/01/06/statins-may-do-doubleduty-on-heart-disease-and-cancer

45. Sacks FM, Pfeffer MA, Moye LA, et al. The effect of pravastatin on coronary events after myocardial infarction in patients with average cholesterol levels. Cholesterol and Recurrent Events Trial investigators. N Engl J Med. 1996;335:1001-9.

46. Ford I, Murray H, Packard CJ, Shepherd J, Macfarlane PW, Cobbe SM on behalf of the West of Scotland Coronary Prevention Study Group. Long-term follow-up of the West of Scotland Coronary Prevention Study. N Engl J Med. 2007;357:1477-86.

47. Author Manuscripts in PMC Accessed at https://www.ncbi.nlm.nih.gov/pmc/about/authorms/

48. Gannon F. The essential role of peer review. EMBO Rep. 2001 Sep 15; 2(9): 743. doi: 10.1093/embo-reports/kve188

49. Grants and Funding: Peer Review. Accessed at https://grants.nih.gov/grants/peer-review.htm. Last accessed on April 16, 2020.

50. Qualls N, Levitt A, Kanade N. et al. Community Mitigation Guidelines to Prevent Pandemic Influenza - United States, 2017. Carrie Reed MMWR Recomm Rep. 2017 Apr 21; 66(1): 1-32. Published online 2017 Apr 21. doi: 10.15585/mmwr.rr6601a1.

51. Wu, Jianqing and Zha, Ping, Comparison Between the Medical Model and Health Optimization Model (January 1, 2020). Available at SSRN: https://ssrn.com/abstract=3512605

52. List of incurable diseases. From Wikipedia, the free encyclopedia. Accessed at https://en.wikipedia.org/wiki/List_of_incurable_diseases

53. Booth FW, Roberts CK, Laye MJ. Lack of exercise is a major cause of chronic diseases. Compr Physiol. 2012;2:1143-1211. 
54. Cormie P, Zopf EM, Zhang X, Schmitz KH. The Impact of Exercise on Cancer Mortality, Recurrence, and Treatment-Related Adverse Effects. Epidemiologic Reviews, Volume 39, Issue 1, January 2017, Pages 71-92.

55. Holmes MD, Chen WY, Feskanich D, et al. Physical activity and survival after breast cancer diagnosis. JAMA. 2005;293(20):2479-2486.

56. Meyerhardt JA, Heseltine D, Niedzwiecki D, et al. Impact of physical activity on cancer recurrence and survival in patients with stage III colon cancer: findings from CALGB 89803. J Clin Oncol. 2006;24(22):3535-3541.

57. Ogino S, Fuchs CS, Giovannucci E. "How many molecular subtypes? Implications of the unique tumor principle in personalized medicine". Expert Rev Mol Diagn. 2012;12(6): 621-8.

58. Ogino S, Lochhead P, Chan AT, et al. "Molecular pathological epidemiology of epigenetics: Emerging integrative science to analyze environment, host, and disease". Mod Pathol. 2013;26 (4): 465-84.

59. DeVol R. and Bedroussian A. An Unhe althy America: The Economic Burden of Chronic Disease. October 2007. Milken Institute Report. Page 1-35.

60. Goldstein S. Morgan Stanley releases new forecast showing U.S. economy may drop as much as 38\%. April 3, 2020. Accessed at https://www.marketwatch.com/story/morgan-stanley-releases-new-forecastshowing-us-economy-may-drop-as-much-as-38-2020-04-03 